\title{
Intestinal Development and Histomorphometry of Broiler Chickens Fed Trichoderma reesei Degraded Date Seed Diets
}

\author{
Salem R. Alyileili ${ }^{1 *}$, Khaled A. El-Tarabily ${ }^{2,3,4 *}$, Ibrahim E. H. Belal ${ }^{1}$, Wissam H. Ibrahim ${ }^{5}$, \\ Mohsin Sulaiman ${ }^{1}$ and Ahmed S. Hussein ${ }^{1}$ \\ ${ }^{1}$ Department of Integrative Agriculture, College of Food and Agriculture, United Arab Emirates University, Al Ain, \\ United Arab Emirates, ${ }^{2}$ Department of Biology, College of Science, United Arab Emirates University, Al Ain, \\ United Arab Emirates, ${ }^{3}$ Khalifa Center for Genetic Engineering and Biotechnology, United Arab Emirates University, \\ Al Ain, United Arab Emirates, ${ }^{4}$ College of Science, Health, Engineering and Education, Murdoch University, Murdoch, WA, \\ Australia, ${ }^{5}$ Department of Food, Nutrition and Health, College of Food and Agriculture, United Arab Emirates University, \\ Al Ain, United Arab Emirates
}

OPEN ACCESS

Edited by:

Vincenzo Tufarelli,

University of Bari Aldo Moro, Italy

Reviewed by:

Justyna Batkowska

University of Life Sciences of

Lublin, Poland

Nesrein M. Hashem,

Alexandria University, Egypt

*Correspondence:

Salem R. Alyileill

salem_alyileili@uaeu.ac.ae

Khaled A. El-Tarabily

ktarabily@uaeu.ac.ae

Specialty section:

This article was submitted to Animal Nutrition and Metabolism,

a section of the journal

Frontiers in Veterinary Science

Received: 06 March 2020

Accepted: 19 May 2020

Published: 18 August 2020

Citation:

Alyileili SR, El-Tarabily KA, Belal IEH,

Ibrahim WH, Sulaiman $M$ and

Hussein AS (2020) Intestinal

Development and Histomorphometry

of Broiler Chickens Fed Trichoderma

reesei Degraded Date Seed Diets.

Front. Vet. Sci. 7:349.

doi: 10.3389/fvets.2020.00349
A study was conducted to investigate the impact of degraded date pits (DDP) on the development and morphology of the intestine in broilers. Trichoderma reesei was used to produce the DDP using a solid-state degradation method. One hundred and eighty broilers were divided into six treatments in triplicate groups of 10 chicks each. The dietary treatments were: positive control with corn-soy basal diet, negative control with corn-soy basal diet $+20 \%$ oxytetracycline at $0.05 \%$, corn-soy basal diet $+10 \%$ DDP, cornsoy basal diet $+0.2 \%$ mannan-oligosaccharides (MOS), corn-soy basal diet $+0.2 \%$ mannose and corn-soy basal diet $+0.1 \%$ mannose for 6 weeks. The results indicate that a 10\% DDP diet increased the activities of the pancreatic enzymes, the villus length, and the villus/crypt ratio, and decreased the crypt depth of the intestine. In conclusion, when compared to oxytetracycline and MOS, DDP can be used as a replacement for antibiotic growth promoters for broilers while improving gut development and intestinal health.

Keywords: broilers, degraded date pits, intestine development, pancreatic enzymes, villus

\section{INTRODUCTION}

In poultry, the gut is a critical site where nutrient uptake takes place. In recent years, intense studies have been focused on gut health for increasing poultry production (1). Hindered functioning of the gut causes impaired digestion, nutrient malabsorption, and decreased growth performance of poultry. The subtherapeutic use of antibiotics increases the thickening of the intestine, which promotes nutrient absorption and reduces the beneficial bacterial count (2). Therefore, recent research has evaluated the use of feed supplements to decrease the adverse effects of prolonged use of antibiotics for improving growth performance and intestine development (3). Considerable interest has been shown in the use of alternatives such as probiotics, prebiotics, synbiotics, herbal medicines, and fermented feeds to improve broiler performance and to influence the bacterial ecology of their gastrointestinal tract.

Prebiotics may be included as a substitute for antibiotics in order to limit the negative impact of antibiotics on animal and human health, and the environment. Prebiotics are non-digestible food ingredients and widely used in animal nutrition (4). Prebiotics produced naturally from plant 
waste may be useful and affordable sources for animal nutrition to improve the gut ecosystem and thus animal performance. Prebiotics positively affect the host by influencing the growth of intestinal bacteria and thereby stimulating immunity and overall performance (5). A commercial prebiotic yeast extract ingredient, namely mannan-oligosaccharides (MOS) has been widely used in poultry rations, which regulates intestinal development and prevents the growth of pathogenic microbes in chicken gastrointestinal (GI) tracts (6). Enhanced immune system and intestinal mucosa with improved morphology and growth were observed in chickens fed MOS included diets. In domesticated animals, prebiotics in the form of non-digestible inulin-type fructans are widely used. The beneficial microbial populations in birds' gut were improved by the supplementation of prebiotics or fermentable sugars instead of antibiotics, and nowadays the use of prebiotics seems to be popular in the poultry industry (7).

Date palm (Phoenix dactylifera L.) is one of the major fruit crops in most Arabian countries. Date pits (DP) are widely produced as byproducts from date confectionery industry. In poultry feed, the imported corn or other cereals could be partly replaced with DP. About $11-18 \%$ of date fruit weight is the seed which is composed of carbohydrates, dietary fiber, fat, ash, and protein (8). The growth performance of broilers fed DP diet at levels ranging from 5 to $27 \%$ suggested no deleterious effect (9). The body weight gain (BWG) and feed conversion ratio (FCR) of chicks fed a diet containing 10-15\% DP were significantly increased after the first 2 weeks of the experiment $(8,10)$. Several reports showed the beneficiary effect of date fiber on growth performance and the carcass characteristics of broilers and layers (11-14).

Solid-state degradation (SSD) of DP with exogenous microbial enzymes such as xylanases enhances the production of simpler forms of carbohydrate molecules from fibers present in the DP (15). A considerable investigation is currently concentrated on the cellulolytic filamentous fungus, Trichoderma reesei. Lignocellulose and galactomannan found in DP act as the natural substrates of $T$. reesei which enhances growth of microbes and activation of several catabolic enzymes. When DP is subjected to degradation, enzymes, such as cellulases, hemicellulases, and pectinases, secreted by $T$. reesei catalyzes the degeneration of complex substrates to simple sugars, thus enhancing its nutritional composition. Degradation improves the chemical constituents of DP and SSD is one of the reasonable methods to prepare degraded date pits (DDP) by using T. reesei. Microbially degraded feeds and enzymes can be better utilized by animals and improve the growth performance and bacterial ecology of their gastrointestinal tract (16). The advantage of using enzymatically degraded prebiotics such as DDP in animal feed is that it promotes the beneficial role of non-digestible sugars in increasing the immune system of the animal.

\footnotetext{
Abbreviations: DP, date pits; DDP, degraded date pits; MOS, mannanoligosaccharides; CSBD, corn-soy basal diet; ME, metabolizable energy; $\mathrm{CP}$, crude protein; EE, ether extract; CF, crude fat; NFE, nitrogen-free extract (starch + sugar); SAS, statistical analyses software; GLM, general linear model; SE, standard error; NSP, non-starch polysaccharide; SSD, solid-state degradation.
}

DDP can act as a prebiotic like MOS which modulates the ecosystem of the animal gut. The mechanism for regulating the bacterial population in the intestine is by binding it to pathogenic bacteria, which possess type-1 fimbriae, such as Escherichia coli and Salmonella species, and by blocking bacterial lectin. It also regulates the production of cytokines and antibodies, improving gut development and overall broiler health. The prebiotic molecules will be degraded into individual sugars and byproducts after absorption and then eliminated from the animal's body through the metabolic process (17). This property of a natural growth promoter derived from DP is a milestone in animal feed research. Hence, the objective of the study was to investigate the impact of DDP on carcass characteristics, intestinal development, morphology, and pancreatic digestive enzyme activity in broilers and to compare its effect with MOS.

\section{MATERIALS AND METHODS \\ Chicks, Diets and Experimental Design}

Chicks were managed and handled according to animal welfare guidelines of the United Arab Emirates (UAE) University Research Ethics Committee, which recommends the rights and welfare of the experimental animals.

Fresh DP (Phoenix dactylifera L.), Khalas variety were obtained from Al Saad date processing factory in Al-Ain, UAE. Each seed was about $2-2.5 \mathrm{~cm}$ long and $6-8 \mathrm{~mm}$ thick. A medium-size mill (Skiold A/S, Kjeldgaardsvej 3, Saeby 9300, Denmark) was used to grind the DP. The size of the pits was reduced to about $1 \mathrm{~mm}$.

The $T$. reesei used in the current study was cultivated as described (18). Four lyophilized T. reesei ampoules were purchased from Deutsche Sammlung von Mikroorganismen und Zellkulturen GmbH (DSMZ), Braunschweig, Germany. A subsample from the re-hydrated $T$. reesei culture was transferred to potato dextrose broth (PDB; Lab M Ltd., Lancashire, United Kingdom) amended with $250 \mu \mathrm{g} \mathrm{mL}^{-1}$ chloramphenicol (Sigma-Aldrich Chemie GmbH, Taufkirchen, Germany) and 100 $\mu \mathrm{g} \mathrm{mL}{ }^{-1}$ streptomycin sulfate (Sigma-Aldrich). A rotary shaker (Model G76, New Brunswick Scientific, Edison, NJ, USA) was used to incubate the flasks at $250 \mathrm{rpm}$ at $25 \pm 2{ }^{\circ} \mathrm{C}$ in the dark for 7 days. The flasks were visually examined daily for fungal growth.

Pure $T$. reesei cultures were maintained on potato dextrose agar (PDA; Lab M Ltd.) plates. The incubation of the plates was carried out in the dark at $25 \pm 2{ }^{\circ} \mathrm{C}$ for 7 days and visually examined daily for fungal growth. The fungus was maintained on full spelling for PDA plates and stored at $4^{\circ} \mathrm{C}$.

The T. reesei DDP was produced using a SSD method inside an incubator, as described (18). Briefly, the ground DP were mixed, cleaned, and sterilized at $121^{\circ} \mathrm{C}$ for $30 \mathrm{~min}$. Sterilized DP were added to each cone of the SSD system. The starter culture of T. reesei prepared on PDA was added to each cone of the SSD system containing the sterilized DP. More cultures and sterilized DP were added in layers to the SSD system until the solution volume reached $8 \mathrm{~L}$ per cone. A continuous supply of disinfected 
TABLE 1 | Composition and calculated chemical analysis of experimental starter diets on dry matter basis for broilers.

\begin{tabular}{|c|c|c|c|c|c|c|}
\hline Ingredients, \% & T1 & T2 & T3 & T4 & T5 & T6 \\
\hline Yellow corn & 55.4 & 55.35 & 44.6 & 55.2 & 55.3 & 55.2 \\
\hline Soybean meal & 36 & 36 & 33.25 & 36 & 36 & 36 \\
\hline Salt & 0.4 & 0.4 & 0.38 & 0.4 & 0.4 & 0.4 \\
\hline Limestone & 1.1 & 1.1 & 1.1 & 1.1 & 1.1 & 1.1 \\
\hline Di-calcium phosphate & 1.56 & 1.56 & 1.2 & 1.56 & 1.56 & 1.56 \\
\hline Vit. + Min. Premix ${ }^{a}$ & 1 & 1 & 1 & 1 & 1 & 1 \\
\hline DL-methionine & 0.24 & 0.24 & 0.25 & 0.24 & 0.24 & 0.24 \\
\hline Lysine & 0 & 0 & 0.1 & 0 & 0 & 0 \\
\hline Corn oil & 2 & 2 & 5.02 & 2 & 2 & 2 \\
\hline Fish meal & 2.3 & 2.3 & 3.1 & 2.3 & 2.3 & 2.3 \\
\hline Oxytetracycline & 0 & 0.05 & 0 & 0 & 0 & 0 \\
\hline Degraded date pits & 0 & 0 & 10 & 0 & 0 & 0 \\
\hline Mannan-oligosaccharides & 0 & 0 & 0 & 0.2 & 0 & 0 \\
\hline Mannose & 0 & 0 & 0 & 0 & 0.2 & 0.1 \\
\hline \multicolumn{7}{|c|}{ Calculated and determined chemical composition ( $\%$ of DM basis) } \\
\hline ME, MJ/kg diet & 12.82 & 12.82 & 12.95 & 12.90 & 12.74 & 12.69 \\
\hline Crude protein & 21.33 & 21.33 & 21.2 & 21.30 & 21.12 & 21.30 \\
\hline Methionine & 0.46 & 0.46 & 0.45 & 0.45 & 0.44 & 0.45 \\
\hline Methionine + cysteine & 0.85 & 0.85 & 0.95 & 0.97 & 0.87 & 0.89 \\
\hline Lysine & 1.07 & 1.07 & 1.33 & 1.29 & 1.17 & 1.15 \\
\hline Threonine & 0.85 & 0.85 & 0.87 & 0.88 & 0.86 & 0.86 \\
\hline Crude fiber & 3.36 & 3.36 & 4.19 & 4.36 & 3.0 & 3.36 \\
\hline Calcium & 0.89 & 0.89 & 0.92 & 0.90 & 0.92 & 0.94 \\
\hline Available phosphorus & 0.46 & 0.46 & 0.45 & 0.4 & 0.51 & 0.55 \\
\hline Sodium & 0.21 & 0.21 & 0.22 & 0.20 & 0.21 & 0.21 \\
\hline
\end{tabular}

T1, Positive control; T2, Negative control; T3, CSBD + 10\% DDP; T4, CSBD + 0.2\% MOS; T5, CSBD + 0.2\% mannose; T6, CSBD + 0.1\% mannose. a Supplementary levels of vitamins and trace elements (per Kg):Vitamin A, 5,484 U; Vitamin $D_{3}, 2,822 \mathrm{U}$; Vitamin E (as DL alpha-tocopherol acetate) $26 \mathrm{IU}$; Vitamin K (as menadione sodiumbisulfite), $4.38 \mathrm{mg}$; Thiamine, 5.94 mg; Riboflavin, 6.2 mg; Pyridoxine, $4.5 \mathrm{mg}$; Cyanocobalamin, $0.14 \mathrm{mg}$; Niacin (as nicotinic acid), $44.1 \mathrm{mg}$; D-pantothenic acid, $15 \mathrm{mg}$; Folic acid, 990 $\mu$ g, Biotin, 0.23 mg; Iron, 120 mg; Copper, 8 mg; Manganese, 83 mg; Cobalt, 5 mg; Zinc, $60 \mathrm{mg}$; lodine, $1.11 \mathrm{mg}$; Selenium, $300 \mu \mathrm{g}$. CSBD, corn-soy basal diet.

moistened air to the SSD system was from a small air pump and a Aquafine ultraviolet lamp. The SSD system was kept in the dark with $90 \%$ humidity at $30 \pm 2{ }^{\circ} \mathrm{C}$ for 3 weeks. At the end of the third week, the procedure of degradation was stopped, and the DDP collected and kept in a refrigerator $\left(4^{\circ} \mathrm{C}\right)$ until use. In our previous study, we analyzed the chemical composition of DDP and published the results (19).

Diets were formulated as indicated in Tables 1, 2. All diets were isonitrogenous and isocaloric. The calculated nutrient composition of the dietary treatments was based on the ingredient composition tables (20). All feed ingredients were ground to a suitable size and mixed in a commercial mixer (Hobart mixer, HL1400, USA) for $20 \mathrm{~min}$. Vitamin and mineral premixes, fish meal, and oil were added gradually with continuous mixing. The wet mix was then passed through a commercial mixer for $15 \mathrm{~min}$ for homogenous distribution of the nutrients and particle sizes. The wet mix was then used for diet preparation.
TABLE 2 | Composition and calculated chemical analysis of experimental finisher diets on dry matter basis for broilers.

\begin{tabular}{|c|c|c|c|c|c|c|}
\hline Ingredients, \% & T1 & T2 & T3 & T4 & T5 & T6 \\
\hline Yellow corn & 64.6 & 64.55 & 52.14 & 64.4 & 64.4 & 64.5 \\
\hline Soybean meal & 28.4 & 28.4 & 26.0 & 28.4 & 28.4 & 28.4 \\
\hline Salt & 0.42 & 0.42 & 0.33 & 0.42 & 0.42 & 0.42 \\
\hline Limestone & 1.33 & 1.33 & 1.15 & 1.33 & 1.33 & 1.33 \\
\hline Di-calcium phosphate & 1.05 & 1.05 & 0.8 & 1.05 & 1.05 & 1.05 \\
\hline Vit. + Min. Premix & 0.2 & 0.2 & 0.2 & 0.2 & 0.2 & 0.2 \\
\hline DL-methionine & 0.2 & 0.2 & 0.3 & 0.2 & 0.2 & 0.2 \\
\hline Lysine & 0.1 & 0.1 & 0.18 & 0.1 & 0.1 & 0.1 \\
\hline Corn oil & 2.5 & 2.5 & 5.9 & 2.5 & 2.5 & 2.5 \\
\hline Fish meal & 1.2 & 1.2 & 3 & 1.2 & 1.2 & 1.2 \\
\hline Degraded date pits & 0 & 0 & 10 & 0 & 0 & 0 \\
\hline Oxytetracycline & 0 & 0.05 & 0 & 0 & 0 & 0 \\
\hline Mannan-oligosaccharides & 0 & 0 & 0 & 0.2 & 0 & 0 \\
\hline Mannose & 0 & 0 & 0 & 0 & 0.2 & 0.1 \\
\hline Total & 100 & 100 & 100 & 100 & 100 & 100 \\
\hline \multicolumn{7}{|c|}{ Calculated and determined chemical composition (\% of DM basis) } \\
\hline ME, MJ/kg diet & 13.12 & 13.12 & 13.12 & 13.12 & 13.12 & 13.12 \\
\hline Crude protein & 17.75 & 17.55 & 17.72 & 17.75 & 17.75 & 17.75 \\
\hline Methionine & 0.47 & 0.47 & 0.49 & 0.47 & 0.47 & 0.47 \\
\hline Methionine + cysteine & 0.86 & 0.86 & 0.84 & 0.86 & 0.86 & 0.86 \\
\hline Lysine & 1.05 & 1.05 & 1.1 & 1.05 & 1.05 & 1.05 \\
\hline Threonine & 0.71 & 0.71 & 0.73 & 0.71 & 0.71 & 0.71 \\
\hline Crude fiber & 3.09 & 3.09 & 3.92 & 3.09 & 3.09 & 3.09 \\
\hline Calcium & 0.82 & 0.82 & 0.80 & 0.82 & 0.82 & 0.82 \\
\hline Available phosphorus & 0.39 & 0.39 & 0.38 & 0.39 & 0.39 & 0.39 \\
\hline Sodium & 0.20 & 0.20 & 0.20 & 0.20 & 0.20 & 0.20 \\
\hline
\end{tabular}

T1, Positive control; T2, Negative control; T3, CSBD + 10\% DDP; T4, CSBD + 0.2\% MOS; T5, CSBD + 0.2\% mannose; T6, CSBD + 0.1\% mannose. a Supplementary levels of vitamins and trace elements (per Kg):Vitamin A, 5,484 U; Vitamin $D_{3}, 2,822 \mathrm{IU}$; Vitamin E (as DL alpha-tocopherol acetate) $26 \mathrm{IU}$; Vitamin K (as menadione sodiumbisulfite), $4.38 \mathrm{mg}$; Thiamine, $5.94 \mathrm{mg}$; Riboflavin, $6.2 \mathrm{mg}$; Pyridoxine, $4.5 \mathrm{mg}$; Cyanocobalamin, $0.14 \mathrm{mg}$; Niacin (as nicotinic acid), $44.1 \mathrm{mg}$; D-pantothenic acid, $15 \mathrm{mg}$; Folic acid, 990

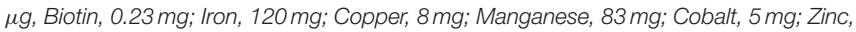
$60 \mathrm{mg}$; lodine, $1.11 \mathrm{mg}$; Selenium, $300 \mu \mathrm{g}$. CSBD, corn-soy basal diet.

\section{Digestive Enzyme Activity in Pancreas, and Weight, Length, and Histomorphology of the Intestinal Segments}

A total of 180 Brazilian "Cobb 500" broiler chicks were divided into six treatments, each containing three replicates of 10 unsexed broilers. Birds within each treatment were designated to three replicate groups ( $n=10$ /group). Chickens were housed as 10 chicks per cage $(50 \mathrm{~cm} \times 45 \mathrm{~cm} \times 45 \mathrm{~cm})$ in an environmentally controlled house. Feed and water were given on an ad libitum basis. The light-dark cycle was 23:1 daily from the $4 \mathrm{~d}$ of the experiment. Vaccination and medical care were carried out under the supervision of veterinaries. The experiment lasted for 42 days.

The treatments consisted of positive control diet (T1), negative control diet (T2), corn-soy basal diet (CSBD) $+10 \%$ DDP (T3), CSBD + 0.2\% MOS (T4), CSBD + 0.2\% mannose (T5), and CSBD $+0.1 \%$ mannose (T6). The pancreatic and gut 
TABLE 3 | Effect of different dietary treatments on carcass characteristics and organ weight of broilers on day 42 of age $(n=6$ chicks per treatment, mean \pm SE).

\begin{tabular}{|c|c|c|c|c|c|c|}
\hline Parameters & \multicolumn{6}{|c|}{ Dietary treatments } \\
\hline Carcass, $g$ & $1,550 \pm 24.6^{\mathrm{a}}$ & $1,604 \pm 12^{\mathrm{a}}$ & $1,696 \pm 12^{\mathrm{a}}$ & $1,665 \pm 10^{\mathrm{a}}$ & $1,628 \pm 59^{a}$ & $1,561 \pm 39^{a}$ \\
\hline Dressing, $\%$ & $68.0 \pm 1.3^{\mathrm{a}}$ & $67.7 \pm 1.5^{\mathrm{a}}$ & $71.7 \pm 0.18^{a}$ & $71.0 \pm 0.7^{\mathrm{a}}$ & $70.7 \pm 0.6^{\mathrm{a}}$ & $69.0 \pm 1.4^{\mathrm{a}}$ \\
\hline Breast, $g$ & $706 \pm 7.6^{c}$ & $760 \pm 7.6^{\mathrm{ab}}$ & $762 \pm 9.2^{\mathrm{a}}$ & $755 \pm 5^{\mathrm{ab}}$ & $722 \pm 7^{\mathrm{bc}}$ & $704 \pm 10.8^{c}$ \\
\hline Liver, g & $49.3 \pm 0.3^{c}$ & $55.3 \pm 0.4^{\mathrm{a}}$ & $55.5 \pm 0.7^{\mathrm{a}}$ & $54.6 \pm 0.4^{a}$ & $48.7 \pm 0.3^{c}$ & $49.3 \pm 1.5^{c}$ \\
\hline Heart, g & $14.2 \pm 0.3^{c}$ & $15.3 \pm 0.18^{a}$ & $14.8 \pm 0.06^{b}$ & $14.6 \pm 0.03^{b}$ & $14.7 \pm 0.07^{\mathrm{b}}$ & $13.8 \pm 0.3^{c}$ \\
\hline Gizzard, g & $30.9 \pm 2.16^{a}$ & $32.2 \pm 3.23^{a}$ & $33.5 \pm 3.33^{\mathrm{a}}$ & $34.0 \pm 2.97^{\mathrm{a}}$ & $30.0 \pm 4.65^{\mathrm{a}}$ & $30.4 \pm 2.92^{\mathrm{a}}$ \\
\hline Spleen, g & $2.41 \pm 0.09^{a}$ & $2.82 \pm 0.2^{\mathrm{a}}$ & $2.91 \pm 0.3^{a}$ & $3.10 \pm 0.2^{\mathrm{a}}$ & $2.70 \pm 0.4^{\mathrm{a}}$ & $2.51 \pm 0.1^{\mathrm{a}}$ \\
\hline Proventriculus, g & $4.29 \pm 0.46^{a}$ & $5.75 \pm 0.53^{a}$ & $6.21 \pm 0.38^{a}$ & $6.41 \pm 0.48^{a}$ & $5.40 \pm 0.77^{\mathrm{a}}$ & $6.10 \pm 0.63^{a}$ \\
\hline
\end{tabular}

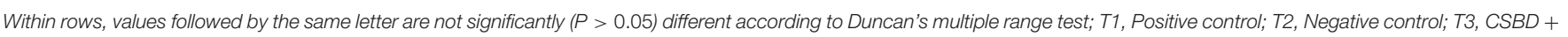

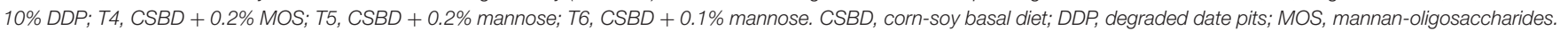

samples were collected from two broilers of each replicate per treatment (6 birds/treatment) and were slaughtered randomly at both 21 and 42 days of age. Samples of the pancreas and different intestinal segments (duodenum, jejunum, and ileum) were collected at different periods. The amylase, protease, and lipase activities were measured using the method of Gertler and Nitsan (21). The weight $(\mathrm{g})$ and length $(\mathrm{cm})$ of intestinal segments were calculated by the method of Ling et al. (22). The histomorphology of broiler intestine was analyzed by the method of Sun et al. (23).

\section{Statistical Analysis}

Data of each experiment were subjected to the analysis of variance (one-way ANOVA) using a general linear model (GLM), and the mean comparisons were performed using Duncan's multiple range test to compare significant differences between the means for all analyses. Analysis of variance was completed using the software SPSS for Windows (Version 20.0, SPSS Inc., Chicago, IL, USA). The replicate was the experiment unit. Data in percentage were transformed to arcsine before analysis.

\section{RESULTS}

\section{Effect of Different Dietary Treatments on Carcass Characteristics and Organ Weight of Broilers}

Table 3 shows the effect of different dietary treatments on the organ weight of broilers. The results showed that there was no significant difference between the live weights of broilers fed different diets. The cold carcass weight and dressing percentage were similar in all dietary treatment groups. The weight of the heart, liver, breast, and thighs was significantly raised in all dietary treatments compared to broilers fed control diets.

\section{Effect of Different Dietary Treatments on the Weight of Duodenum, Jejunum and Ileum}

The weight of duodenum at 21 and 42 days of age was increased significantly in only the 10\% DDP diet-fed broilers and the $0.2 \%$ MOS diet-fed broilers when compared to other groups at the same age (Table 4). On day 21 of the experiment, the weight of jejunum was similar in all diet-fed broilers, while on day 42 the weight of jejunum was increased significantly in 10\% DDP dietfed broilers and $0.2 \%$ MOS diet-fed broilers when compared to the positive control. In negative control broilers and mannose diet-fed broilers, the weight of jejunum was decreased, and the result was comparable to positive control diet-fed broilers. The weight of the ileum at 21 and 42 days was significantly higher in $10 \%$ DDP diet-fed broilers and 0.2\% MOS diet-fed broilers when compared to other treatments (Table 4).

\section{Effect of Different Dietary Treatments on Length of Duodenum, Jejunum, and Ileum}

The length of the duodenum was increased significantly in $10 \%$ DDP diet-fed broilers and $0.2 \%$ MOS diet-fed broilers when compared to the positive control (Table 5). On day 21 and day 42, in broilers fed a CSBD with or without antibiotic and a mannose diet, the length of the duodenum was smaller when compared to $10 \%$ DDP diet-fed broilers and MOS diet-fed broilers. The result was comparable to the positive control. On day 21, the length of jejunum was increased significantly in 10\% DDP dietfed broilers and $0.2 \%$ MOS diet-fed broilers when compared to other treatments. The other treatments were substantially similar. On day 42 of the experiment, the jejunum length was increased significantly in only MOS diet-fed broilers when compared to other treatments except for those fed a 10\% DDP diet. The 10\% DDP treatment was intermediate. On day 21 of the experiment, the length of ileum was the same in all treatments. On day 42 of the trial, the length of ileum was shown to be increased 
TABLE 4 | Effect of different dietary treatments on weight (g) and length ( $\mathrm{cm})$ of duodenum, jejunum and ileum of broilers $(n=6$ chicks per treatment, mean \pm SE).

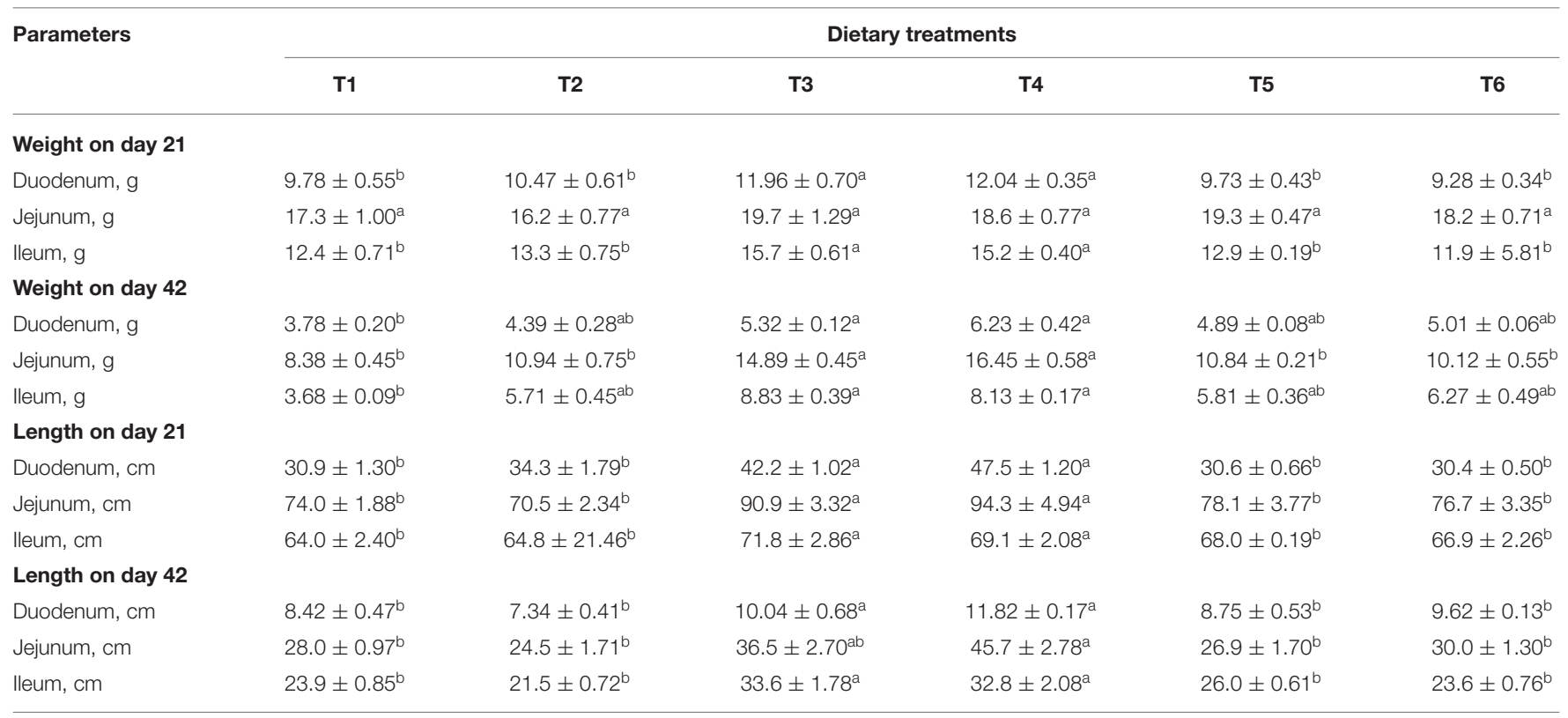

Within rows, values followed by the same letter are not significantly ( $P$ > 0.05) different according to Duncan's multiple range test; T1, Positive control; T2, Negative control; T3, CSBD + $10 \%$ DDP; T4, CSBD + 0.2\% MOS; T5, CSBD + 0.2\% mannose; T6, CSBD + 0.1\% mannose. CSBD, corn-soy basal diet; DDP, degraded date pits; MOS, mannan-oligosaccharides.

TABLE 5 | Effect of different dietary treatments on histomorphometry of duodenum, jejunum and ileum of broilers ( $n=6$ chicks per treatment, mean \pm SE).

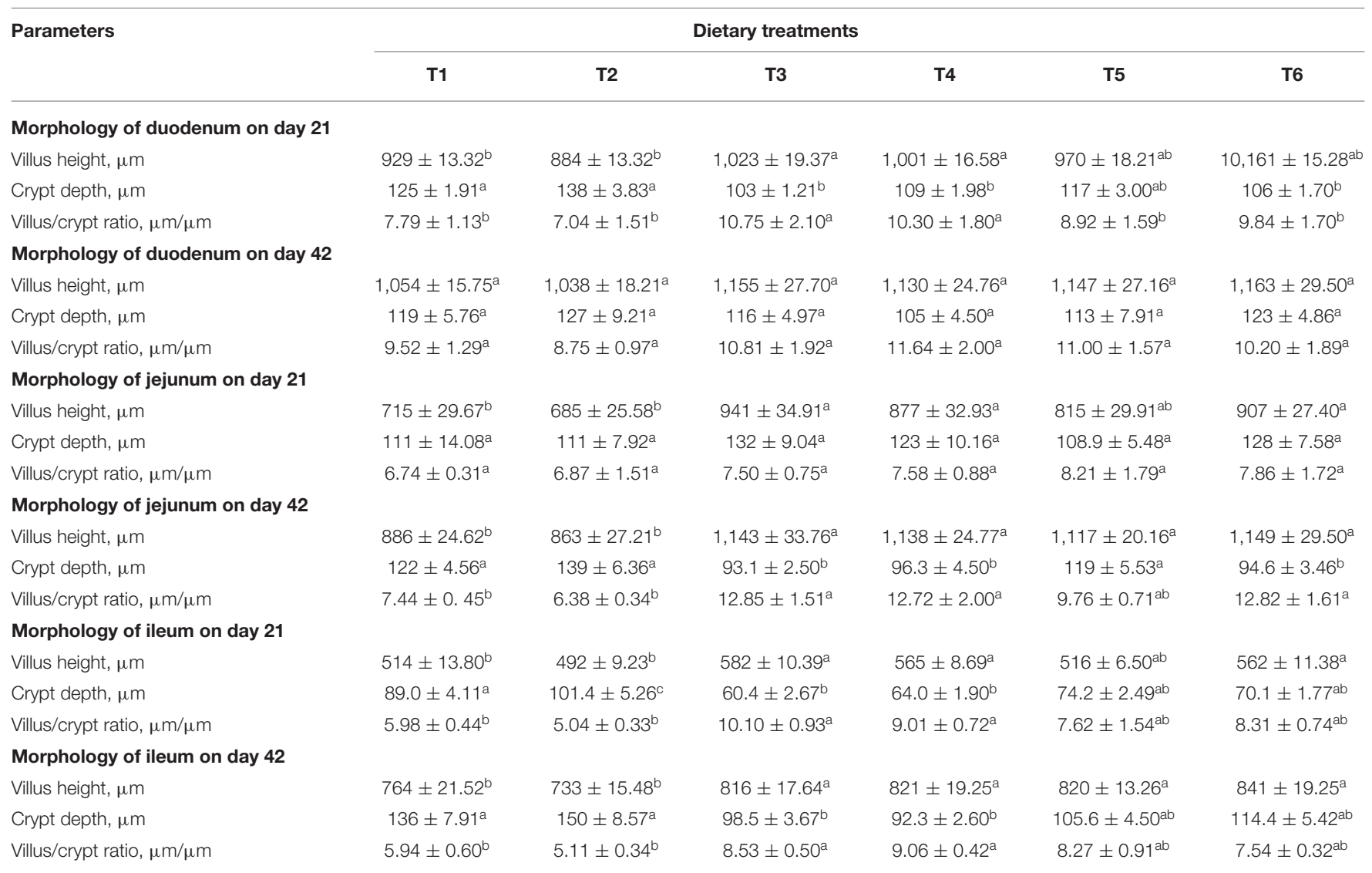

Within rows, values followed by the same letter are not significantly $(P>0.05)$ different according to Duncan's multiple range test; T1, Positive control; T2, Negative control; T3, CSBD + $10 \%$ DDP; T4, CSBD + 0.2\% MOS; T5, CSBD + 0.2\% mannose; T6, CSBD + 0.1\% mannose. CSBD, corn-soy basal diet; DDP, degraded date pits; MOS, mannan-oligosaccharides. 
TABLE 6 | Effect of different dietary treatments on the activity of digestive enzymes $\left(U \mathrm{mg}^{-1}\right.$ protein) of the pancreas of broiler chickens $(n=6$ chicks per treatment, mean $\pm \mathrm{SE})$.

\begin{tabular}{|c|c|c|c|c|c|c|}
\hline \multirow[b]{2}{*}{ Parameters } & \multicolumn{6}{|c|}{ Dietary treatments } \\
\hline & T1 & T2 & T3 & T4 & T5 & T6 \\
\hline Amylase & $411 \pm 20.70^{b}$ & $470 \pm 16.54^{b}$ & $526 \pm 19.94^{a}$ & $517 \pm 17.49^{a}$ & $496 \pm 16.58^{b}$ & $502 \pm 15.27^{b}$ \\
\hline Protease & $4,926 \pm 262.70^{a}$ & $5,054 \pm 108.28^{a}$ & $5,577 \pm 139 \cdot 27^{a}$ & $5,305 \pm 164.69^{a}$ & $5,101 \pm 118.24^{a}$ & $5,166 \pm 124.61^{a}$ \\
\hline Lipase & $58.4 \pm 5.21^{b}$ & $52.3 \pm 7.74^{b}$ & $83.2 \pm 12.49^{a}$ & $96.2 \pm 12.44^{a}$ & $60.5 \pm 3.73^{b}$ & $59.8 \pm 4.80^{b}$ \\
\hline
\end{tabular}

Within rows, values followed by the same letter are not significantly $(P>0.05)$ different according to Duncan's multiple range test; T1, Positive control; T2, Negative control; T3, CSBD + $10 \%$ DDP; T4, CSBD + 0.2\% MOS; T5, CSBD + 0.2\% mannose; T6, CSBD + 0.1\% mannose. CSBD, corn-soy basal diet; DDP, degraded date pits; MOS, mannan-oligosaccharides.

significantly in broilers fed a $10 \%$ DDP diet and a $0.2 \%$ MOS diet when compared to other treatments.

\section{Effect of Different Dietary Treatments on Histomorphology of Intestine}

Results showed that the villus height, crypt depth and villus crypt ratio of the duodenum were significantly raised in broilers fed a $10 \%$ DDP diet and $0.2 \%$ MOS diet on day 21 when compared to control-diet broilers and mannose diet-fed broilers. On day 42 , there was no significant variation between villus height, crypt depth, and villus crypt ratio of the duodenum of broilers fed different dietary treatments (Table 5). On day 21 and day 42, the villus height of jejunum was significantly increased in broilers fed $10 \%$ DDP diet compared to other treatments. The crypt depth of jejunum was decreased significantly in broilers fed $10 \%$ DDP diet on day 42 , and no significant change was observed in the villus crypt ratio of different dietary treatments during the experimental period (Table 5). In the ileum, the villus height was significantly increased in 10\% DDP diet-fed broilers, $0.2 \%$ MOS diet-fed broilers, and $0.1 \%$ mannose diet-fed broilers on days 21 and 42 . During the experimental period, crypt depth of ileum was decreased in broilers fed 10\% DDP diet and a mannose diet-fed broilers. In broilers fed a 10\% DDP diet and a $0.2 \%$ MOS diet the villus/crypt ratio of ileum was significantly increased on days 21 and 42 when compared to the positive and negative control (Table 5).

\section{Effect of Different Dietary Treatments on Pancreatic Enzymes}

The activity of the pancreatic enzymes amylase and lipase were observed to be significantly higher in 10\% DDP diet-fed broilers and $0.2 \%$ MOS diet-fed broilers when compared to other treatments. The activity of protease was similar in all treatments (Table 6).

\section{DISCUSSION}

The present results indicated that microbial treatment leads to the catabolism and degradation of main macronutrients such as carbohydrates, protein, and fatty acids, accompanied by an increase in simple sugars, free amino acids, and organic acids. The crude fiber content of DDP was found to be $20.8 \%$, ash $(2.09 \%)$, crude fat $(7.2 \%)$, protein $(5.56 \%)$, and total carbohydrate (87.2\%). Neutral detergent fiber (NDF) and acid detergent fiber (ADF) were found to be 74.6 and $45.7 \%$, respectively. Monosaccharide composition of fiber showed that the degradation with $T$. reesei significantly $(P<0.05)$ enhanced the glucose and mannose content of cellulose, hemicellulose, and lignin. Pectin, total carbohydrate, and the MOS content were also increased in DDP, in which galactose and mannose were the major neutral sugars. Among the studied minerals, potassium, calcium, magnesium, sulfur, and phosphorus were predominant. The phenolic and flavonoid contents of DDP significantly $(P<0.05)$ increased after treatment with $T$. reesei. Among the studied minerals in DDP, potassium, calcium, magnesium, sulfur, and phosphorus were predominant. DDP also showed marked activities of antioxidant such as $2,2^{\prime}$-azinobis (3-ethylbenzothiazoline 6 sulphonic acid) (ABTS), Ferric Reducing Antioxidant Power (FRAP) assays, and 2,2-diphenyl1-picrylhydrazyl (DPPH) (19).

Several studies have shown the beneficial influences of prebiotics on carcass characteristics of broilers. In the present study, the dressing yield for broiler fed 10\% DDP was $71.6 \%$, and $71.0 \%$ for those fed $0.2 \%$ MOS. Increases in carcass output of broilers of our study were higher than those reported by Rao et al. (24), who concluded that the dressing yield ranged from 63.7 to $66.7 \%$ of commercial Cobb broilers. The carcass yield was $71.0 \%$ at 42 days of age, which was similar to the value observed by Abdel-Raheem and Abd-Allah (25). They also reported that broiler thigh and breast weight were elevated after adding single or combined dietary supplements of MOS and probiotics. Yeast based MOS supplementation improved carcass characteristics and blood biochemical parameters in broiler chickens (26). Similar results were seen in our present study. The current findings agreed with (27-29), who reported that prebiotics, probiotics, and synbiotics had no significant positive effect on carcass yields of quails and broilers. MOS supplementation in broiler diets had no significant effect on dressing percentage and gizzard, spleen, proventriculus, and bursa weight (30). The addition of MOS at a dose of $3 \mathrm{~g} / \mathrm{kg}$ feed improved the carcass characteristics and intestinal microbial ecology of growing Japanese quails (25). Broilers fed palm kernel meal diet reduces the relative size of broiler organs, which reduces the relative weight of such organs (31).

The development of intestine is a critical factor, and the weight of intestinal parts reflects the physiological status and function of broilers (32). Intestine enhances immunization and 
regulates digestion and absorption of nutrients. The development of the intestine was reflected by the relative length and weight of organs. In our study, the increased length and weight of the intestine proves that dietary supplementation with $10 \%$ DDP stimulates the intestinal development of broilers. It is established that the longer the length of the intestine the greater will be the absorption of nutrients. The role of intestinal parts, mainly the jejunum in digestion and absorption of broilers, is reflected by an increase in length and height of its epithelial cells (33). Broilers fed DDP had longer jejunum, which showed supplementation of broiler diet with $10 \%$ DDP plays a marked role in the development of jejunum, the major site for digestion and absorption. Replacement of chicks diet with 15\% DP had a higher weight percentage of small intestine parts such as jejunum when compared to control treatment group (14). There were reports that high fiber contents increased length and weight of intestine of broilers (34). The results of the present study agreed with similar findings of DP diet-fed broiler chicks, which showed increased weight and length of the intestine (11). Chemical analysis showed that DDP contains a substantial amount of fiber (19), and the fiber content promotes the absorption of nutrients by the intestinal segments, which elevates the length and weight of the intestine.

Morphometric results of the duodenum, jejunum, and ileum in broilers on day 42 of the experiment revealed that DDP treatment enhances the health of the digestive tract by altering the villus height and crypt depth. Absorption of nutrients is promoted by longer villi and shallower crypts with greater surface area, which activates maturation of the intestinal cells and digestive enzyme activity $(35,36)$. The crypt is the production site where divisions of stem cells occur to allow villus renewal. The higher duodenal and jejunal villi height of broilers fed a diet containing 10\% DDP showed the enhancement of the villi surface area. This suggests that the addition of $10 \%$ DDP enhances the absorption of nutrients, improves the resistance to disease, and increases overall growth performance. The 10\% DDP diet-fed broilers showed shallow crypt depth and increased villus crypt ratio in the duodenum, jejunum, and ileum, which indicates the positive role of DDP in the development of broilers GI tract. MOS has been observed to raise villus height and reduce crypt depth in poultry (37). Reports showed that MOS decreased the crypt depth in the small intestines of broilers and encouraged their rapid growth $(38,39)$. Previous studies have shown that broilers fed fructooligosaccharides, one of the common prebiotics had improved intestinal structure and morphology (40). In broilers fed MOS together with enzymes have shown an increase in perimeter and height of villi of the duodenum and ileum, which increased the absorption surface of the intestinal segments (41). An increased villus height and crypt depth were observed in broilers fed enzyme-treated palm kernel expeller (42), while in broilers fed fermented palm kernel expeller up to $36 \%$ decreased intestine villus height was observed (43). Previous research showed that high fiber content of palm kernel meal stimulated the development of the mucosa epithelial cells confirmed by higher and wider villus in broiler chickens fed $25 \%$ palm kernel meal diet (44). The present study also supports the above finding that fiber content of DDP plays an important role in the altered morphology of broilers intestine.
The digestive enzymes play an important role in the decomposition of absorbed nutrients into small molecules for utilization of broilers (45). Results showed that in broilers fed $10 \%$ DDP diet an enhanced activity of the pancreatic enzymes amylase and lipase were observed. Different factors, such as the animal age, secretion of digestive juice, and composition of diets, influence the activities of enzymes (46). Amylase, produced by the pancreas, hydrolyses starch into smaller units that can be absorbed in the bird intestine (47). The activity of digestive enzymes was increased in broilers fed MOS (48). Increased activity of amylase, lipase, and protease was observed in broiler chicks supplemented with fructose oligosaccharide up to $4.0 \mathrm{~g} / \mathrm{kg}$ when compared to the control corn diet-fed broilers (40). The increase in $\alpha$ amylase activity in the gut in the DDP-supplemented broilers indicates that DDP enhances the secretion of the enzyme from the pancreas. Pancreatic lipase and amylase stimulate the digestion and absorption of nutrients, which leads to a healthy intestine of broilers and enhances the growth performance of the birds.

\section{CONCLUSIONS}

DDP had beneficial effects in broilers that can be used as a locally produced and affordable feed additive and an inexpensive feed ingredient. Inclusion of both 10\% DDP and 0.2\% MOS in broilers rations improved carcass characteristics and intestine development. The enhancement of digestive enzymes activity indicates that DDP provide a healthy gut for the digestion and absorption of ingested nutrients. It can be concluded that DDP can act as a prebiotic similar to MOS, and supplementation of DDP can be fed as an alternative promising growth promoter in poultry feeding.

\section{DATA AVAILABILITY STATEMENT}

The datasets generated for this study are available on request to the corresponding authors.

\section{ETHICS STATEMENT}

The animal study was reviewed and approved by the scientific committee of the Department of Integrative Agriculture, College of Food and Agriculture, United Arab Emirates University.

\section{AUTHOR CONTRIBUTIONS}

All authors listed have made a substantial, direct and intellectual contribution to the work, and approved it for publication.

\section{ACKNOWLEDGMENTS}

The authors would like to express their gratitude to the Department of Integrative Agriculture, College of Food and Agriculture, United Arab Emirates University for their financial (Grant number 313072), and technical and valuable help throughout the study. 


\section{REFERENCES}

1. Alsaffar AA, Attia YA, Mahmoud MB, Zewell HS, Bovera F. Productive and reproductive performance and egg quality of laying hens fed diets containing different levels of date pits with enzyme supplementations. Trop Anim Health Pro. (2013) 45:327-34. doi: 10.1007/s11250-012-0222-1

2. Biely P, Kluepfel D, Morosoli R, Shareck F. Mode of action of three endo- $\beta$ 1, 4-xylanases of Streptomyces lividans. Biochim Biophys Acta Protein Struct Molec Enzym. (1993) 1162:246-54. doi: 10.1016/0167-4838(93)90288-3

3. Cheled-Shoval SL, Amit-Romach E, Barbakov M, Uni Z. The effect of in ovo administration of mannan oligosaccharide on small intestine development during the pre-and post-hatch periods in chickens. Poult Sci. (2011) 90:230110. doi: $10.3382 /$ ps.2011-01488

4. Johnson LP, Walton GE, Psichas A, Frost GS, Gibson GR, Barraclough TG. Prebiotics modulate the effects of antibiotics on gut microbial diversity and functioning in vitro. Nutrients. (2015) 7:4480-97. doi: 10.3390/nu 7064480

5. Bozkurt M, Aysul N, Küçükyilmaz K, Aypak S, Ege G, Catli AU, et al. Efficacy of in-feed preparations of an anticoccidial, multienzyme, prebiotic, probiotic, and herbal essential oil mixture in healthy and Eimeria spp.-infected broilers. Poult Sci. (2014) 93:389-99. doi: 10.3382/ps.2013-03368

6. Baurhoo B, Letellier A, Zhao X, Ruiz-Feria CA. Cecal populations of lactobacilli and bifidobacteria and Escherichia coli populations after in vivo Escherichia coli challenge in birds fed diets with purified lignin or mannanoligosaccharides. Poult Sci. (2007) 86:2509-16. doi: $10.3382 /$ ps.2007-00136

7. Kermanshahi H, Rostami H. Influence of supplemental dried whey on broiler performance and cecal flora. Int J Poult Sci. (2006) 5:538-43. doi: 10.3923/ijps.2006.538.543

8. Hussein AS, Alhadrami GA, Khalil YH. The use of dates and date pits in broiler starter and finisher diets. Bioresour Technol. (1998) 66:219-23. doi: 10.1016/S0960-8524(98)00054-6

9. Vandepopuliere JM, AL-Yousef Y, Lyons JJ. Dates and date pits as ingredients in broiler starting and coturinx quail breeder diets. Poult Sci. (1995) 74:113442. doi: $10.3382 / \mathrm{ps} .0741134$

10. Kamel BS, Diab MF, Ilian MA, Salman AJ. Nutritional value of whole dates and date pits in broiler rations. Poult Sci. (1981) 60:1005-11. doi: 10.3382/ps.0601005

11. AL-Marzooki W, AL-Halhali A, AL-Maqbaly R, Ritchie A, Annamalai K, Forsberg NE. Date fiber as a constituent of broiler starter diets. J Agric Mar Sci. (2000) 5:59-61. doi: 10.24200/jams.vol5iss2pp59-61

12. Tabook NM, Kadim IT, Mahgoub O, Al-Marzooqi W. The effect of date fibre supplemented with an exogenous enzyme on the performance and meat quality of broiler chickens. Br Poult Sci. (2006) 47: 73-82. doi: 10.1080/00071660500475160

13. Salajegheh $\mathrm{MH}$, Yousef-Elahi M, Salarmoini M. Evaluating the nutritional value of date pits and demonstrating their application in laying hen diets. $J$ Anim Physiol Animal Nutr. (2018) 102:e777-86. doi: 10.1111/jpn.12834

14. Hammod AJ, Ali NA, Alkassar AM, Jameel YJ. The effect of partial replacement of maize by date pits on broiler performance. J Pure Appl Microbiol. (2018) 12:807-13. doi: 10.22207/JPAM.12.2.42

15. Foreman PK, Brown D, Dankmeyer L, Dean R, Diener S, Dunn-Coleman NS, et al. Transcriptional regulation of biomass-degrading enzymes in the filamentous fungus Trichoderma reesei. J Biol Chem. (2003) 278:31988-97. doi: 10.1074/jbc.M304750200

16. Belal IEH. Evaluating fungi-degraded date pits as a feed ingredient for Nile tilapia Oreochromis niloticus L. Aquacult Nutr. (2008) 14:445-52. doi: 10.1111/j.1365-2095.2007.00548.x

17. Canibe N, Jensen BB. Fermented and nonfermented liquid feed to growing pigs: effect on aspects of gastrointestinal ecology and growth performance. $J$ Anim Sci. (2003) 81:2019-31. doi: 10.2527/2003.8182019x

18. Hussein AS, Belal IEH, Alyalyali SR, El-Tarabily KA. Date pit composition for the treatment of animals. U.S. Patent No. 9,682,116. Washington, DC: U.S. Patent and Trademark Office (2015).

19. Alyileili SR, Hussein AS, Ibrahim WH, El-Tarabily KA. Phytochemical composition and antioxidant activity of Trichoderma reesei degraded date (Phoenix dactylifera L.) pits. Curr Bioact Compd. (2020) 16:528-36. doi: 10.2174/1573407215666190207093046
20. Hashim IB, Hussein AS, Afifi HS. Quality of breast and thigh meats when broilers are fed rations containing graded levels of sugar syrup. Poult Sci. (2013) 92:2195-200. doi: 10.3382/ps.2012-02940

21. Gertler A, Nitsan Z. The effect of trypsin inhibitors on pancreatopeptidase E, trypsin, chymotrypsin and amylase in the pancreas and intestinal tract of chicks receiving raw and heated soya-bean diets. Br J Nutr. (1970) 24:893-904. doi: 10.1079/BJN19700094

22. Ling J, Feng L, Liu Y, Jiang J, Jiang WD, Hu K, et al. Effect of dietary iron levels on growth, body composition and intestinal enzyme activities of juvenile Jian carp (Cyprinus carpio var. Jian). Aquacult Nutr. (2010) 16:61624. doi: 10.1111/j.1365-2095.2009.00699.x

23. Sun H, Tang JW, Yao XH, Wu Y, Wang X, Feng J. Effects of dietary inclusion of fermented cottonseed meal on growth, cecal microbial population, small intestinal morphology, and digestive enzyme activity of broilers. Trop Anim Health Prod. (2013) 45:987-93. doi: 10.1007/s11250-012-0322-y

24. Rao SVR, Prakash B, Raju MVLN, Panda AK, Poonam S, Murthy OK. Effect of supplementing organic selenium on performance, carcass traits, oxidative parameters and immune responses in commercial broiler chickens. AsianAustralas J Anim Sci. (2013) 26:247-52. doi: 10.5713/ajas.2012.12299

25. Abdel-Raheem SM, Abd-Allah SM. The effect of single or combined dietary supplementation of mannan oligosacharide and probiotics on performance and slaughter characteristics of broilers. Int J Poult Sci. (2011) 10:854-62. doi: $10.3923 /$ ijps.2011.854.862

26. Waqas M, Mehmood S, Mahmud A, Naveed S, Hussain J, Ahmad S, et al. Effect of yeast based mannan oligosaccharide (Actigen ${ }^{\mathrm{TM}}$ ) supplementation on growth, carcass characteristics and physiological response in broiler chickens. Indian J Anim Res. (2019) 53:1475-9. doi: 10.18805/ijar.B-923

27. Sahin EZ, Yardimci M. Effects of kefir as a probiotic on growth performance and carcass characteristics in geese (Anser anser). J Anim Vet Adv. (2009) 8:562-7.

28. Chumpawadee S, Chinrasri O, Somchan T, Ngamluan S, Soychuta S. Effect of dietary inclusion of cassava yeast as probiotic source on growth performance, small intestine (ileum) morphology and carcass characteristic in broilers. Int J Poult Sci. (2008) 7:246-50. doi: 10.3923/ijps.2008.246.250

29. Ashayerizadeh O, Dastar B, Shargh MS, Ashayerizadeh A, Rahmatnejad E, Hossaini SMR. Use of garlic (Allium sativum), black cumin seeds (Nigella sativa L.) and wild mint (Mentha longifolia) in broiler chickens diets. J Anim Vet Adv. (2009) 8:1860-3.

30. Sojoudi MR, Dadashbeiki M, Bouyeh M. Effect of different levels of prebiotics TechnoMos on carcass characteristics of broiler chickens. J Basic Appl Sci Res. (2012) 2:6778-94.

31. Esuga PM, Sekoni AA, Omage JJ, Bawa GS. Evaluation of enzyme (Maxigrain $($ ) supplementation of graded levels of palm kernel meal (PKM) on the performance of broiler chickens. Pak J Nutr. (2008) 7:607613. doi: 10.3923/pjn.2008.614.619

32. Zhong G, Shen Y, Zhang S, Wang Q, Song Z, Shi S. Effects of newly harvested corn on growth performance, intestine development and metabolism of nutrients in broilers. Ital J Anim Sci. (2019) 18:505-12. doi: 10.1080/1828051X.2018.1544470

33. Song ZS. Analysis the influenced factors of newly harvested corn on production performance in laying hens. China Poult. (2011) 33:53.

34. Jørgensen H, Zhao XQ, Knudsen KEB, Eggum BO. The influence of dietary fibre source and level on the development of the gastrointestinal tract, digestibility and energy metabolism in broiler chickens. Br J Nutr. (1996) 75:379-95. doi: 10.1079/BJN19960141

35. Adeleye OO, Otakoya IO, Fafiolu AO, Alabi JO, Egbeyale LT, Idowu OMO. Serum chemistry and gut morphology of two strains of broiler chickens to varying interval of post hatch feeding. Vet Anim Sci. (2018) 5:20-5. doi: 10.1016/j.vas.2017.12.001

36. Baurhoo B, Phillip L, Ruiz-Feria CA. Effects of purified lignin and mannan oligosaccharides on intestinal integrity and microbial populations in the ceca and litter of broiler chickens. Poult Sci. (2007) 86:1070-8. doi: $10.1093 / \mathrm{ps} / 86.6 .1070$

37. Baurhoo B, Ferket PR, Zhao X. Effects of diets containing different concentrations of mannan oligosaccharide or antibiotics on growth performance, intestinal development, cecal and litter microbial populations, and carcass parameters of broilers. Poult Sci. (2009) 88:2262-72. doi: $10.3382 /$ ps.2008-00562 
38. Yang Y, Iji PA, Choct M. Dietary modulation of gut microflora in broiler chickens: a review of the role of six kinds of alternatives to in-feed antibiotics. World Poultry Sci J. (2009) 65:97-114. doi: 10.1017/S0043933909000087

39. Sarica S, Corduk M, Yarim GF, Yenisehirli G, Karatas U. Effects of novel feed additives in wheat based diets on performance, carcass and intestinal tract characteristics of quail. S Afr J Anim Sci. (2009) 39:144-57. doi: 10.4314/sajas.v39i2.44388

40. Xu ZR, Hu CH, Xia MS, Zhan XA, Wang MQ. Effects of dietary fructo oligosaccharide on digestive enzyme activities, intestinal microflora and morphology of male broilers. Poult Sci. (2003) 82:1030-6. doi: $10.1093 / \mathrm{ps} / 82.6 .1030$

41. Oliveira MC, Rodrigues EA, Marques RH, Gravena RA, Guandolini GC, Moraes VMB. Performance and morphology of intestinal mucosa of broilers fed mannan-oligosaccharides and enzymes. Arq Bras Med Vet Zootec. (2008) 60:442-8. doi: 10.1590/S0102-093520080002 00025

42. Saenphoom P, Liang JB, Ho YW, Loh TC, Rosfarizan M. Effects of enzyme treated palm kernel expeller on metabolizable energy, growth performance, villus height and digesta viscosity in broiler chickens. Asian-Australas J Anim Sci. (2013) 26:537-44. doi: 10.5713/ajas.20 12.12463

43. Rahim F, Sabrina S, Rusmawati R, Syibli M. Broiler small intestine villi response to feed containing palm kernel cake which fermented with Rhizopus sp. J Indon Trop Anim Agric. (2007) 32:251-6.

44. Zulkifli I, Iman-Rahayu HS, Alimon AR, Vidyadaran MK, Babjee SA. Gut micoflora and intestinal morphology of commercial broiler chickens and red jungle fowl fed diets containing palm kernel meal. Arch Geflugelk. (2009) 73:49-55.

45. Cui XY, Wang SM, Yuan JM, Zhang BK, Yan DR. Maize at different storage periods: effects on immune function of broilers. Chin J Animal Nutr. (2013) 25:849-55.

46. Sun J, Yan SM. Research progress of digestive tract development and enzyme activity in ruminants. Feed Res. (2015) 1:24-8.

47. Jung SJ, Houde R, Baurhoo B, Zhao X, Lee BH. Effects of galactooligosaccharides and a Bifidobacteria lactis-based probiotic strain on the growth performance and fecal microflora of broiler chickens. Poult Sci. (2008) 87:1694-9. doi: 10.3382/ps.2007-00489

48. Yang Y, Iji PA, Choct M. Effects of different dietary levels of mannanoligosaccharide on growth performance and gut development of broiler chickens. Asian-Australas J Anim Sci. (2007) 20:1084-91. doi: 10.5713/ajas.2007.1084

Conflict of Interest: The authors declare that the research was conducted in the absence of any commercial or financial relationships that could be construed as a potential conflict of interest.

Copyright (C) 2020 Alyileili, El-Tarabily, Belal, Ibrahim, Sulaiman and Hussein. This is an open-access article distributed under the terms of the Creative Commons Attribution License (CC BY). The use, distribution or reproduction in other forums is permitted, provided the original author(s) and the copyright owner(s) are credited and that the original publication in this journal is cited, in accordance with accepted academic practice. No use, distribution or reproduction is permitted which does not comply with these terms. 